\title{
Percutaneous endoscopic gastrostomy in children
}

\author{
Wael El-Matary MD MRCP MRCPCH UK
}

\begin{abstract}
W El-Matary. Percutaneous endoscopic gastrostomy in children. Can J Gastroenterol 2008;22(12):993-998.

Percutaneous endoscopic gastrostomy has been a valuable tool in nutritional rehabilitation since its inception in 1980. Although it was originally described in children, a large sector of the adult population is dependant on it for nutritional support. Percutaneous endoscopic gastrostomy tube insertion is generally a safe procedure. Nevertheless, variable incidence rates of complications have been reported. The present review highlights the up-to-date indications, contraindications and complications of percutaneous endoscopic gastrostomy in children, along with a discussion of issues that need further exploring through future research.
\end{abstract}

\section{La gastrostomie endoscopique percutanée chez les enfants}

La gastrostomie endoscopique percutanée est un outil précieux pour la réadaptation nutritionnelle depuis sa création en 1980. Bien qu'à l'origine, elle ait été décrite chez les enfants, un vaste secteur de la population adulte en dépend pour le soutien nutritionnel. En général, l'insertion de la sonde de gastrostomie endoscopique percutanée est une intervention sécuritaire. Néanmoins, on a déclaré des taux de complications d'incidence variable. La présente analyse souligne les indications à jour, les contre-indications et les complications de la gastrostomie endoscopique percutanée chez les enfants, de même qu'un exposé des enjeux qui ont besoin d'une exploration plus approfondie par de futures recherches.

Key Words: Endoscopic; Gastrostomy; Percutaneous

$\mathrm{N}$ asogastric tube feeding is most often used for short-term enteral tube feeding. Several limitations for its long-term use have been reported including nasal discomfort, blockage or displacement of the tube, irritation or penetration of the larynx, recurrent pulmonary aspiration and decreased survival rates (1).

Gastrostomy, in which a tube is inserted directly into the stomach through an opening in the anterior abdominal wall, has been used since the 1980s to bypass gastrointestinal dysfunction (2). The primary goal of this procedure is to improve physical well-being by reversing or preventing malnutrition. Other goals are said to be establishing a procedure for giving medications with improved compliance and effectiveness $(2,3)$. Today, gastrostomy can be performed surgically, radiologically, laparoscopically or endoscopically (percutaneous endoscopic gastrostomy [PEG]). PEG has been used increasingly in children and adults, especially in those with disabilities.

\section{HISTORICAL BACKGROUND}

PEG was first introduced by Gauderer (2) in 1980. The original description of PEG was in children; however, it has become a popular method of enteral nutrition in all age groups. The first PEG insertion was performed in the pediatric operating room of the University Hospital of Cleveland, USA on June 12 , 1979, on a four-and-half month-old baby with inadequate intake (2). Interestingly, the procedure took place under local anesthesia with sedation. The initial reactions varied between enthusiasm and skepticism. Nevertheless, PEG is now the second most common indication for upper tract endoscopy in hospitalized patients in the United States. Approximately 4\% of the total number of patients needing PEG in the United States are children (2).

\section{TECHNIQUE}

The theory of PEG is based on the simple fact that the continuous, sutureless opposition of stomach to the peritoneum and anterior abdominal wall by a feeding tube will lead to formation of adhesions, ie, a tract around the tube (2). Since the original report by Gauderer (2), several modifications of the original technique have been introduced $(2,4-8)$. The most popular technique of insertion is the 'pull' technique because it has many advantages over the other techniques especially in young children (2). In children, PEG tube insertion is performed under general anesthesia. After insertion of the gastroscope into the stomach and a gentle insufflation of air, the most transluminant point of indentation on the anterior abdominal wall is marked. A single dose of intravenous antibiotic is given. After sterilizing the skin of the anterior abdominal wall and infiltration of this point with local anesthesia, a skin incision of approximately $0.5 \mathrm{~cm}$ is made. A trocar with a needle is pushed through this point into the stomach under complete endoscopic visualization. A thread or a guide wire is inserted through the trocar after removing the needle and this thread is snared. The endoscope is then withdrawn with the snare holding the thread. A suitably sized PEG tube is then connected to the thread and the thread is pulled from the

Division of Pediatric Gastroenterology, Hepatology and Nutrition, Stollery Children's Hospital, Faculty of Medicine, University of Alberta, Edmonton, Alberta

Correspondence: Dr Wael El-Matary, Division of Pediatric Gastroenterology, Faculty of Medicine, University of Alberta, 9222 Aberhart Centre 1, 11402 University Avenue, Edmonton, Alberta T6G 2J3. Telephone 780-407-3339, fax 780-407-3507,

e-mail WaelElMatary@Capitalhealth.ca, elmatary@Ualberta.ca

Received for publication July 30, 2008. Accepted August 18, 2008 
skin incision pulling the tube into the patient's mouth through the esophagus, to be retained in the stomach by the internal bolster. An external bolster is placed loosely on the skin. The position of the inner opening of the tube should be checked by endoscopy (2).

\section{Postoperative care}

Opinions vary whether to apply dressing on the tube site; there is no evidence whether this will affect the outcome. In the past, hospital staff waited $24 \mathrm{~h}$ before commencing use of the tube. Now, there is convincing evidence that delaying use of the tube has no advantage over early feeding (9). At the Stollery Children's Hospital, Edmonton, Alberta, we recommend use of the tube $4 \mathrm{~h}$ after insertion, first with sterile water and if tolerated, proceed to formula. We normally keep children overnight for observation and for teaching of caregivers. Starting the following day, the tube should be rotated $180^{\circ}$ daily to reduce the possibility of gastric mucosal erosion or migration.

\section{INDICATIONS}

Failure of adequate intake due to impossible or inadequate oral intake.

For short durations of inadequate intake, nasoenteral tube feeding can be used. The durations after which PEG is recommended varies between two and 12 weeks (10).

Children with the following conditions fall under this category:

Neurological disorders with inability to swallow or dysphagia: This is the main and most common indication for PEG in children and adults $(11,12)$. The majority of the children are suffering from cerebral palsy with inability to swallow. Some of these patients may also suffer from epilepsy, in which case they will need the tube for medication intake. Recurrent aspiration secondary to neurological disorder may result in failure to use the oral route safely and the insertion of a PEG tube should be undertaken (13).

Although the nutritional status of these children improves after PEG insertion, long-term quality of life is yet to be determined. Morbidity and mortality of 98 children with significant neurological dysfunction and PEG were examined in a retrospective study (14). The range of follow-up duration was six to 14 years. There was a significant increase in weight-for-age Z-scores. Nevertheless, mortality reached up to $39 \%$ after 13 years due to associated comorbid conditions. Although 15\% of these children developed severe gastroesophageal reflux disease (GERD) after PEG that necessitated fundoplication, GERD was not a predictor of mortality

Craniofacial abnormalities: Children with congenital craniofacial problems or those with severe head trauma who may need prolonged pediatric intensive care admission may benefit from PEG to ensure adequate nutritional support and avoid the side effects of prolonged nasoenteral feeding $(15,16)$.

Oncology problems with malnutrition: Cancer patients are likely to be in catabolic states, which will negatively affect their nutritional status. Aggressive nutritional rehabilitation is very important in improving the outcome in this sector of patients. With the underlying malignancy, in addition to the aggressive chemo- and radiotherapy, it is not uncommon to have difficulty in establishing adequate nutrition via the oral route. Gastrostomy tubes could be a valuable avenue for nutritional support (17). They also serve as a way to give medications if the oral route is difficult to use. PEG has been proven to be a safe and effective method for nutritional rehabilitation in children with cancer (18). Nevertheless, it is advisable to avoid PEG insertion during periods of neutropenia $(18,19)$.

Other clinical conditions: PEG can be used in other clinical conditions that lead to wasting and malnutrition (eg, chronic renal failure, cystic fibrosis, metabolic problems, chronic infection such as HIV, cardiac disorders, short bowel syndrome and Crohn's disease) (20). Nutritional support in children with chronic health problems is crucial. Patients with cystic fibrosis could establish not only better nutritional states but also better pulmonary function if nocturnal supplementary PEG feeding is started early in life (21). Supplementary PEG feeding is also proven important in other chronic conditions, such as Crohn's disease. In fact, nutritional therapy is proven effective and safe if given via PEG in children with Crohn's disease who may have compliance issues with this line of therapy (22). PEG could be also a good and practical way for giving medications to children with chronic conditions such as chronic renal failure, HIV or chronic metabolic problems (20).

\section{Recurrent documented aspiration}

Occasionally, children who are developmentally normal and have no underlying chronic neurological condition may suffer from chronic aspiration (23). This may have a negative effect on their pulmonary function and their quality of life. Nasoenteral feeding could be proven effective in improving their pulmonary function but again, it is not practical for long durations. PEG is a practical and safe way for nutritional support and fluid intake especially in children with short bowel syndrome or motility problems $(20,24)$.

\section{Gastric drainage and decompression}

PEG is rarely indicated for gastric drainage and decompression, especially in children with short bowel syndrome or motility problems $(20,24)$.

\section{Absolute (1,20,24,25)}

\section{CONTRAINDICATIONS}

1. Bleeding disorders with an international normalized ratio of greater than 1.5, a partial thromboplastin time of greater than $50 \mathrm{~s}$ and/or a platelet count of less than $50 \times 10^{9} / \mathrm{L}$ (unless corrected);

\section{Severe ascites;}

\section{Peritonitis;}

4. Pharyngeal/esophageal obstruction; and

5. PEG insertion should not be attempted during periods of acute severe illness but should be performed when the patient is in stable condition.

\section{Relative}

1. Interposed organs (liver, colon), distorted anatomy by multiple abdominal surgeries, severe kyphoscoliosis, or any other condition that leads to failure of diaphonoscopy (transillumination through abdominal wall) or clear point of indentation $(3,20,26,27)$. In the past, these conditions were considered to be absolute contraindications but now many gastroenterologists and 
surgeons do not consider them as such. At the Stollery Children's Hospital, we prefer to perform laparoscopicassisted PEG tube insertion for children with these conditions because we believe it is safer.

2. Although immune deficiencies are not considered to be a contraindication, PEG insertions with possibility of serious skin/wound infections should be highlighted to the referring physician/patients' family and should be avoided if possible.

\section{COMPLICATIONS}

Generally speaking, PEG tube insertion is a safe procedure. The procedure should not lead to mortalities per se; however, death has been reported due to comorbid conditions (14). Generally speaking, it is recommended not to use PEG during periods of severe disease (eg, acute heart failure) or severe immunosuppression. Death has been reported post-PEG insertion when it is attempted during these periods $(28,29)$ (Table 1$)$.

Major complications have been reported with variable incidence $(5 \%$ to $17 \%)$ in different published pediatric series $(15,28,29,30)$.

\section{Major complications}

Major infection: Skin cellulitis, peritonitis, peritoneal abscess and fasciitis have been reported with variable incidence after PEG insertion. The routine use of prophylactic antibiotics have been examined in several randomized, controlled trials. A recent meta-analysis (31) that included 10 randomized controlled trials indicated that antibiotic prophylaxis resulted in a RR reduction of $62 \%$ (95\% CI $48 \%$ to $72 \%$ ) and an absolute risk reduction of $15 \%$ (95\% CI $10 \%$ to $19 \%$ ). The numberneeded-to-treat to prevent one wound infection was seven (95\% CI five to 10). There was no significant difference in the sensitivity analysis regarding the type of antibiotic used (penicillin versus cephalosporins) or the number of doses of antibiotic (one versus three). In our centre, we normally administer one dose of a first-generation cephalosporin perioperatively.

Superficial minor skin infections are extremely common but skin cellulitis may occur in the immediate postoperative period, especially if the external bolster is too tight on the skin surface. This could result in ischemic changes and may predispose to serious skin infection and necrosis that can respond to loosening of the external bolster and intravenous antibiotics (32).

Pneumoperitoneum is a frequent finding post-PEG insertion. In the absence of symptoms, it should be left alone because it normally resolves within $48 \mathrm{~h}$ post-PEG insertion $(26,33)$.

Peritonitis secondary to gastric content leak has been reported early, either due to failure of tract formation possibly as a result of a very loose external bolster, or late due to disruption of the formed tract $(29,34)$. Some patients could be managed conservatively but many of these patients may need laparotomy. Occasionally, peritonitis may occur secondary to colonic perforation with or without fistula formation.

Colonic fistula/perforation formation: Colonic perforation with subsequent acute peritonitis or with fistula formation and early or late presentation has been reported in both adult and pediatric series (Table 1). The fistula is usually gastrocolocutaneous. In many of these patients, the operator cannot establish a good point of indentation and transillumination during PEG insertion because a colonic loop finds its way between the anterior abdominal wall and the stomach. Presentation could be in the form of vomiting and abdominal pain with stool coming from the PEG site. Presentation can be delayed up to several months following PEG insertion. Some children were reported to respond to conservative management in the form of PEG removal, intravenous antibiotics and keeping them nil per os for some time. Others will need laparotomy and surgical correction $(28,29)$.

Major bleeding: Major bleeding necessitating blood transfusion with or without laparotomy, although uncommon, has been reported in both adult and pediatric series (Table 1). This may happen if there is anatomical variation (eg, previous abdominal surgery or kyphoscoliosis). PEG tubes may be inserted into the greater stomach curvature with perforation of the gastric artery and subsequent intra-abdominal bleeding that necessitates laparotomy.

Tube/bolster migration with or without intestinal obstruction: This was not an uncommon complication, especially in the early days. Nevertheless, with the introduction of better tubes and improvement of the technique, the incidence of bolster migration has dropped significantly. The problem is usually the result of too much traction on the tube or pushing the external bolster too tight on the skin surface, which may result in 'buried bumper' syndrome. On occasion, the tube or internal bolster migrate through the stomach to block the pylorus, or even migrate distally to cause intestinal obstruction. Daily rotation of the tube in the early postinsertion period is recommended to avoid gastric mucosal migration or erosion (27).

Esophageal tear: Although no esophageal injury was reported in the early pediatric series, a longitudinal esophageal tear was reported in a single child in the series by Beasley et al (28). This may be caused by an inappropriate size match between the tube (too large) and esophagus (especially in esophageal strictures). The endoscopist should be aware of any esophageal strictures before inserting PEG tubes. Another reason is that the guide wire may be snared and pulled out too close to the tip (28). Nowadays, the majority of PEG tubes come with a floppy thread rather than a rigid guide wire.

Failure to enter the stomach: Although it has not been considered a complication by some endoscopists/surgeons, failure to insert PEG tubes has been reported in some series as a complication (28). Certainly, exposing a child to general anesthesia with no benefit is not very pleasant; one can argue that doing so may spare the child from major complications. This usually happens when the operator cannot establish a point of satisfactory indentation and transillumination on the anterior abdominal wall. The alternative is to proceed to laparoscopically assisted PEG, laparoscopic gastrostomy tube (35) or open gastrostomy, depending on the availability of the relevant expertise and equipment.

\section{Minor complications}

Minor complications are common and may occur in up to 50\% of patients $(3,15,34)$. Minor complications include minor superficial skin infections that usually respond to enteral antibiotics, superficial granulation tissue formation that usually responds to local chemical cautery using silver nitrate swabs, and tube leak which, in the majority of cases, is due to local infection $(27,28,36)$. Again, this should respond to a course of enteral antibiotics and sometimes suspending PEG feeding for a few days, during which, a nasojejunal feeding tube can be used. 
TABLE 1

Major complications reported in selected pediatric series

\begin{tabular}{|c|c|c|c|c|c|c|c|c|c|}
\hline $\begin{array}{l}\text { Author } \\
\text { (reference) }\end{array}$ & $\mathrm{n}$ & Design & Deaths & Infection & $\begin{array}{c}\text { Tube/bolster } \\
\text { migration }\end{array}$ & $\begin{array}{c}\text { Esophageal } \\
\text { tear }\end{array}$ & Fistula & Obstruction & Bleeding \\
\hline Gauderer et al (29) & 220 & Retrospective & 2 & 3 & 0 & 0 & 5 & 1 & 0 \\
\hline Khattak et al (30) & 120 & Retrospective & 1 & 8 & 1 & 0 & 4 & 3 & 3 \\
\hline Beasley et al (28) & 79 & Prospective & 8 & 8 & 5 & 1 & 1 & 0 & 0 \\
\hline Segal et al $(34)^{\star}$ & 110 & Retrospective & 0 & 4 & $16^{\dagger}$ & 0 & 2 & 0 & 0 \\
\hline Avistland et al $(15)^{\ddagger}$ & 121 & Retrospective & 0 & 10 & 3 & 0 & 0 & 0 & 0 \\
\hline
\end{tabular}

${ }^{*}$ Complications reported six days post-percutaneous endoscopic gastrostomy (PEG) tube insertion; ${ }^{\dagger} 16$ children had 24 episodes of tube/bottom migration during follow-up period; $¥$ Early complications within first 30 days of PEG tube insertion

TABLE 2

Selected pediatric trials examining the effect of percutaneous endoscopic gastrostomy (PEG) tube insertion on gastroesophageal reflux

\begin{tabular}{|c|c|c|c|c|c|c|c|c|c|}
\hline \multirow{2}{*}{$\begin{array}{l}\text { Author } \\
\text { (reference) }\end{array}$} & \multirow[b]{2}{*}{$\mathrm{n}$} & \multirow{2}{*}{$\begin{array}{c}\text { Neuro- } \\
\text { abnormal }\end{array}$} & \multirow{2}{*}{$\begin{array}{c}\text { Reflux } \\
\text { symptoms } \\
\text { pre-PEG }\end{array}$} & \multirow{2}{*}{$\begin{array}{c}\text { Reflux } \\
\text { symptoms } \\
\text { post-PEG }\end{array}$} & \multicolumn{2}{|c|}{$\mathrm{pH}$ before } & \multicolumn{2}{|c|}{$\mathrm{pH}$ after } & \multirow[b]{2}{*}{ Fundoplication } \\
\hline & & & & & Normal & Abnormal & Normal & Abnormal & \\
\hline Grunow et al (40) & 10 & 5 & 0 & 3 & 10 & 0 & 6 & 4 & None \\
\hline Launay et al (41) & 20 & 9 & NS & NS & 13 & 6 & 5 & 1 & None \\
\hline Wilson et al (42) & 121 & 21 & 25 & 6 & 51 & 28 & NS & NS & 2 \\
\hline Sulaeman et al (43) & 85 & 79 & 46 & 20 & 22 & 24 & NS & NS & 8 \\
\hline
\end{tabular}

NS Not stated

Tube clogging is also a frequent problem and families are taught how to flush the tube after feeding to avoid having a formula thrombus.

Another minor complication of PEG is that if the tube falls out early in the postoperative period, there is a risk of peritonitis because the tract around the tube may not be well formed, especially in the first few days. We instruct our patients' families to go to the nearest emergency room as soon as possible if this complication occurs and avoid inserting another tube at home. However, if this problem happens late (eg, six weeks or more after PEG tube insertion), we advise families to insert a Foley catheter that we supply them with until they see us next. By doing so, the tract is kept open and prevents closing immediately following tube removal.

Complications of change or removal: Normally, change of the tube to a skin-level device (eg, Mic-Key button, KimberlyClark, USA) is an easy and safe procedure $(20,37)$. Because buttons are easy to use and more socially acceptable, many patient's families request this change as soon as possible. The change can happen once the tract around the tube is formed and has been reported to be completed in some centres as early as six weeks post-PEG insertion. In the old tubes, the internal bolster was rigid and this necessitated the removal of the bolster endoscopically. Simple cutting of the tube and leaving the internal bolster to be excreted with stools is unsafe and may lead to intestinal obstruction. Yaseen et al (38) recommended against nonendoscopic removal of PEG tubes, especially in small children. Currently, there are tubes available with relatively floppy internal bolsters that can be pulled out, after which a button can be inserted. There have been a few reports (20) of patients who suffered from peritonitis because the end of the button was not in the stomach. It is a safe approach to endoscopically confirm placement of the gastric end of the button.
Normally, after removing the PEG tube, the tract starts closing immediately and in the majority of patients, takes $48 \mathrm{~h}$ to $72 \mathrm{~h}$ to close. Occasionally, a persistent gastrocutaneous fistula may need surgical closure. Factors that may predispose to this rare complication include malnutrition, debilitating disease, persistent straining-like cough and obesity (39). In a recent pediatric series (15), delayed closure (greater than one month) was reported in 10 of 21 children (48\%) who were able to remove their PEG tube during the time of follow-up. Only three of these children needed surgical closure of the fistula. Time from PEG insertion to removal was not predictive of delayed closure.

\section{PEG, GERD AND ASPIRATION}

The causal relationship between PEG insertion and occurrence or aggravation of GERD and subsequent aspiration pneumonia has been the subject of many trials. Generally speaking, pediatric trials have been underpowered with conflicting results and conclusions. Table 2 summarizes the results of four pediatric trials addressing this topic. While the small study by Grunow et al (40) concluded that PEG insertion is associated with significant reflux, other larger and more recent trials had completely different conclusions (41-43).

In the adult literature, Johnson et al (44) demonstrated an increase in lower esophageal sphincter (LES) pressure after PEG insertion in their small sample of seven patients with decreased reflux scores. One patient did not maintain this effect when he was tested again four weeks post-PEG insertion. Coben et al (45) examined the effect of PEG insertion on basal LES pressure during two different methods of feeding. While PEG placement did not affect the LES, rapid infusion of high volume feeds induced significant reduction in pressure in the LES with some reflux episodes detected by scintigraphy. 
In the presence of GERD symptoms previous to PEG insertion, the decision of PEG, to use a gastrostomy tube with fundoplication or even consideration of a jejunostomy or gastrojejunal-tube insertion should be individualized and performed after discussion with referring physicians, surgeons and patients' families. If there is a problem with vomiting and GERD with or without delayed gastric emptying, a $\mathrm{pH}$ study, motility study and/or a gastric emptying scan may help in making the decision and in counselling the patients and their families. An upper gastrointestinal contrast study will help to exclude gastrointestinal anatomical problems in patients with chronic vomiting.

\section{PEG in small infants}

In the past, some endoscopists and surgeons considered the lower limit of body weight to insert PEG tubes to be $10 \mathrm{~kg}$ $(10,20)$. However, PEG has been reported to be inserted safely in infants with a weight as low as $2.3 \mathrm{~kg}(46)$. Other investigators recommended using the laparoscopic-assisted PEG technique in this sector of patients (47).

\section{Family and caregiver satisfaction}

Avistland et al (15) examined parent and caregiver satisfaction using semistructured telephone interviews. Of 85 families interviewed, 78 (92\%) stated that preoperative expectations were fulfilled and 98\% stated that they would choose PEG again. It was not clear in the study how long after PEG insertion the interviews took place.

\section{Ethical dilemma}

The adult literature and guidelines state that, ideally, PEG insertion should not be performed for administrative convenience or to save money, time or human resources unless there will be an improvement in the quality of life rather than just maintaining life (eg, in chronic vegetative states $[20,48,49]$ ). The situation may be different when it comes to children. In many situations in pediatric practice we agree to insert PEG tubes to save time for the caregivers and improve the quality of

\section{REFERENCES}

1. Holmes S. Enteral feeding and percutaneous endoscopic gastrostomy. Nurs Stand 2004;18:41-3.

2. Gauderer MW. Percutaneous endoscopic gastrostomy and the evolution of contemporary long-term enteral access. Clin Nutr 2002;21:103-10.

3. DeLegge RL, DeLegge MH. Percutaneous endoscopic gastrostomy evaluation of device materials: Are we "failsafe"? Nutr Clin Pract 2005;20:613-7.

4. Robertson FM, Crombleholme TM, Latchaw LA, Jacir NN. Modification of the "push" technique for percutaneous endoscopic gastrostomy in infants and children. J Am Coll Surg 1996;182:215-8.

5. Sedlack RE, Pochron NL, Baron TH. Percutaneous endoscopic gastrostomy placement without skin incision: Results of a randomized trial. J Parenter Enteral Nutr 2006;30:240-5.

6. Dye KR, Pattison CP, Dye NV. Percutaneous endoscopic gastrostomy: Technical modifications for improved results. South Med J 1986;79:24-7.

7. Horiuchi A, Nakayama Y, Fujii H, Kajiyama M. Endoscopic holderassisted percutaneous endoscopic gastrostomy placement: Results of a prospective, randomized comparison study. Gastrointest Endosc 2006;64:627-31.

8. Lee WJ, Chao SH, Yu SC, Chen KM. Laparoscopic assisted gastrostomy tube placement. J Laparoendosc Surg 1994;4:201-4.

9. McCarter TL, Condon SC, Aguilar RC, Gibson DJ, Chen YK. Randomized prospective trial of early versus delayed feeding after percutaneous endoscopic gastrostomy placement. Am J Gastroenterol 1998;93:419-21.

10. Pennington C. To PEG or not to PEG. Clin Med 2002;2:250-5.

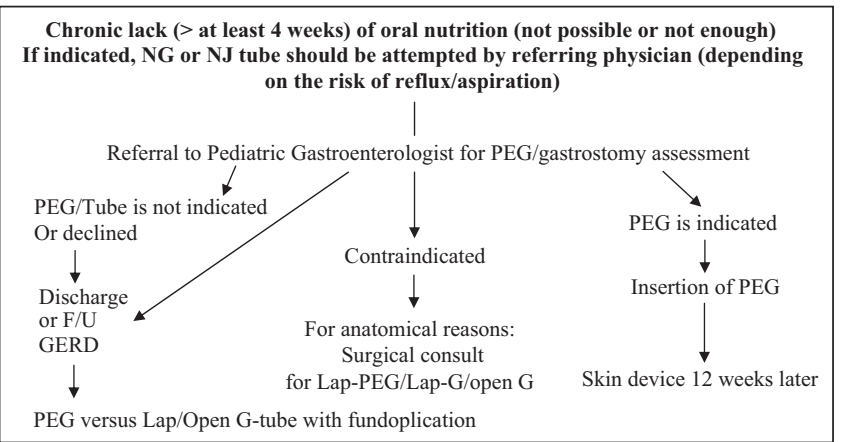

Figure 1) Suggested algorithm for patients who are referred for assessment for percutaneous endoscopic gastrostomy (PEG) tube insertion. F/U Follow-up; G Gastrostomy; GERD Gastroesophageal reflux disease; Lap Laparoscopic; NG Nasogastric; NJ Nasojejunal

life for the family as a whole, despite knowing that the overall disorder (eg, severe cerebral palsy or metabolic problem) will not improve. This area certainly needs to be explored in a detailed multidisciplinary manner.

\section{Practical points}

Figure 1 summarizes a suggested algorithm for children referred for PEG insertion. It should be emphasized that pediatric gastroenterologists must be heavily involved in the decision-making process and should not be viewed merely as technicians. This has also been highlighted in some published adult guidelines (20). The evidence available regarding the superiority of other ways of tube feeding (gastrojejunal tubes) or other techniques used for gastrostomy tube insertion (laparoscopic-assisted or laparoscopic gastrostomy) is growing $(8,35,47,50-55)$. However, it is mainly level III evidence (retrospective studies and case series/reports). More wellplanned, prospective, randomized, controlled trials are needed to explore the safety and cost-effectiveness of these approaches.

11. Miller RE, Castlemain B, Lacqua FJ, Kotler DP. Percutaneous endoscopic gastrostomy: Results in 316 patients and review of literature. Surg Endosc 1989;3:186-90.

12. Nicholson FB, Korman MG, Richardson MA. Percutaneous endoscopic gastrostomy: A review of indications, complications and outcome. J Gastroenterol Hepatol 2000;15:21-5.

13. Safadi BY, Marks JM, Ponsky JL. Percutaneous endoscopic gastrostomy. Gastrointest Endosc Clin N Am 1998;8:551-68.

14. Catto-Smith AG, Jimenez S. Morbidity and mortality after percutaneous endoscopic gastrostomy in children with neurological disabilities. J Gastroenterol Hepatol 2006;21:734-8.

15. Avistland TL, Kristensen C, Emblem R, Veenstra M, Mala T, Bjornland K. Percutaneous endoscopic gastrostomy in children: A safe technique with major symptom relief and high parental satisfaction. J Pediatr Gastroenterol Nutr 2006;43:624-8.

16. Dwyer KM, Watts DD, Thurber JS, Benoit RS, Fakhry SM. Percutaneous endoscopic gastrostomy: The preferred method of elective feeding tube placement in trauma patients. J Trauma 2002; $52: 26-32$.

17. Barlauge M, Kruse A, Scroder H. Percutaneous endoscopic gastrostomy in paediatric cancer patients. Ugeskr Laeger 2008;170:2027-31.

18. Skolin I, Hernell O, Larsson MV, Wahlgren C, Wahlin YB. Endoscopic percutaneous gastrostomy in children with malignant disease. J Pediatr Oncol Nurs 2002;19:154-63.

19. Pederson AM, Kok K, Peterson G, Nielsen OH, Michaelson KF, Schmiegelow K. Percutaneous endoscopic gastrostomy in children with cancer. Acta Paediatr 1999;88:849-52. 
20. Loser C, Asch G, Hebuterne X, et al. ESPEN guidelines on artificial enteral nutrition-percutaneous endoscopic gastrostomy (PEG). Clin Nutr 2005;24:848-61.

21. Williams SG, Ashworth F, McAlweenie A, Poole S, Hodson ME, Westaby D. Percutaneous endoscopic gastrostomy feeding in patients with cystic fibrosis. Gut 1999;44:87-90.

22. Cosgrove M, Jenkins HR. Experience of percutaneous endoscopic gastrostomy in children with Crohn's disease. Arch Dis Child 1997;76:141-3.

23. Loser C, Folsch UR. [Feeding of patients with ENT diseases using an enteral tube system (PEG/PEJ tubes)]. Laryngorhinootologie 2000;79:442-6.

24. Kyle H. PEG--percutaneous endoscopic gastrostomy. Br J Theatre Nurs 1996;6:27-30.

25. Hussain A, Woolfrey S, Massey J, Geddes A, Cox J. Percutaneous endoscopic gastrostomy. Postgrad Med J 1996;72:581-5.

26. Broscious SK. Preventing complications of PEG tubes. Dimens Crit Care Nurs 1995;14:37-41.

27. DeLegge MH. Percutaneous endoscopic gastrostomy. Am J Gastroenterol 2007;102:2620-3.

28. Beasley S, Catto-Smith AG, Davidson PM. How to avoid complications during percutaneous endoscopic gastrostomy? J Pediatr Surg 1995;30:671-3.

29. Gauderer MW. Percutaneous endoscopic gastrostomy: A 10-year experience with 220 children. J Pediatr Surg 1991;26:288-94.

30. Khattak IU, Kimber C, Kiely EM, Spitz L. Percutaneous endoscopic gastrostomy in pediatric practice: Complications and outcome. J Pediatr Surg 1998;33:67-72.

31. Jafri NS, Mahid SS, Minor KS, Idstein SR, Hornung CA, Galandiuk S. Meta-analysis: Antibiotic prophylaxis to prevent peristomal infection following percutaneous endoscopic gastrostomy. Aliment Pharmacol Ther 2007;25:647-56.

32. McClave SA, Jafri NS. Spectrum of morbidity related to bolster placement at time of percutaneous endoscopic gastrostomy: Buried bumper syndrome to leakage and peritonitis. Gastrointest Endosc Clin N Am 2007;17:731-46.

33. Roberts PA, Wrenn K, Lundquist S. Pneumoperitoneum after percutaneous endoscopic gastrostomy: A case report and review. J Emerg Med 2005;28:45-8.

34. Segal D, Michaud L, Guimber D, Ganga-Zandzou PS, Turck D, Gottrand F. Late-onset complications of percutaneous endoscopic gastrostomy in children. J Pediatr Gastroenterol Nutr 2001;33:495-500.

35. Zamakhshary M, Jamal M, Blair GK, Murphy JJ, Webber EM, Skarsgard ED. Laparoscopic vs. percutaneous endoscopic gastrostomy tube insertion: A new pediatric gold standard? J Pediatr Surg 2005;40:859-62.

36. Ganga UR, Ryan JJ, Schafer LW. Indications, complications, and long-term results of percutaneous endoscopic gastrostomy: A retrospective study. S D J Med 1994;47:149-52.

37. Ljungdahl M, Sundbom M. Complication rate lower after percutaneous endoscopic gastrostomy than after surgical gastrostomy: A prospective, randomized trial. Surg Endosc 2006;20:1248-51.

38. Yaseen M, Steele MI, Grunow JE. Nonendoscopic removal of percutaneous endoscopic gastrostomy tubes: Morbidity and mortality in children. Gastrointest Endosc 1996;44:235-8.
39. Peter S, Geyer C, Beglinger. C. Persistent gastrocutaneous fistula after percutaneous gastrostomy tube removal. Endoscopy 2006;38:539-40.

40. Grunow JE, Al-Hafidh AS, Tunell WP. Gastroesophageal reflux following percutaneous endoscopic gastrostomy in children. J Pediatr Surg 1989;24:42-5.

41. Launay V, Gottrand F, Turck MD, Michaud L, Ategbo S, Farriaux JP. Percutaneous endoscopic gastrostomy in children: Influence on gastroesophageal reflux. Pediatrics 1996;97:726-8.

42. Wilson G J P, van der Zee D C, Bax N MA. Endoscopic gastrostomy placement in the child with gastroesophageal reflux: Is concomitant antireflux surgery indicated? J Pediatr Surg 2006;41:1441-5.

43. Sulaeman E, Udall JN, Brown RF, et a. Gastroesophageal reflux and Nissen fundoplication following percutaneous endoscopic gastrostomy in children. J Pediatr Gastroenterol Nutr 1998;26:269-73.

44. Johnson DA, Hacker JF, Benjamin SB, et al. Percutaneous endoscopic gastrostomy effects on gastroesophageal reflux and the lower esophageal sphincter. Am J Gastroenterol 1987;82:622-4.

45. Coben RM, Weintraub A, DiMarino AJ, Cohen S. Gastroesophageal reflux during gastrostomy feeding. Gastroenterology 1994;106:13-8.

46. Wilson L, Oliva-Hemker M. Percutaneous endoscopic gastrostomy in small medically complex infants. Endoscopy 2001;33:433-6.

47. Backman T, Arnbjörnsson E, Berglund Y, Larsson LT. Video-assisted gastrostomy in infants less than 1 year. Pediatr Surg Int 2006;22:243-6.

48. Arvanitakis M, Ballarin A, Van Gossum A. Ethical aspects of percutaneous endoscopic gastrostomy placement for artificial nutrition and hydration. Acta Gastroenterol Belg 2006;69:317-20.

49. Rabeneck L, McCullough LB, Wray NP. Ethically justified, clinically comprehensive guidelines for percutaneous endoscopic gastrostomy tube placement. Lancet 1997;349:496-8.

50. Nozoe T, Anai H. Laparoscopy-assisted replacement of percutaneous endoscopic gastrostomy. J Clin Gastroenterol 2002;34:144-6.

51. Croshaw RL, Nottingham JM. Laparoscopic-assisted percutaneous endoscopic gastrostomy: Its role in providing enteric access when percutaneous endoscopic gastrostomy is not possible. Am Surg 2006;72:1222-4.

52. Edelman DS, Arroyo PJ, Unger SW. Laparoscopic gastrostomy versus percutaneous endoscopic gastrostomy: A comparison. Surg Endosc 1994;8:47-9.

53. Scheer MF, Miedema BW. Laparoscopic assisted percutaneous endoscopic gastrostomy. Surg Laparosc Endosc 1995;5:483-6.

54. Stylianos S, Flanigan LM. Laparoscopy-guided percutaneous button gastrostomy in children after previous abdominal surgery. J Laparoendosc Surg 1995;5:199-201.

55. Yu SC, Petty JK, Bensard DD, Partrick DA, Bruny JL, Hendrickson RJ. Laparoscopic-assisted percutaneous endoscopic gastrostomy in children and adolescents. JSLS 2005;9:302-4. 


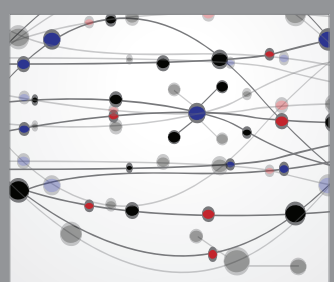

The Scientific World Journal
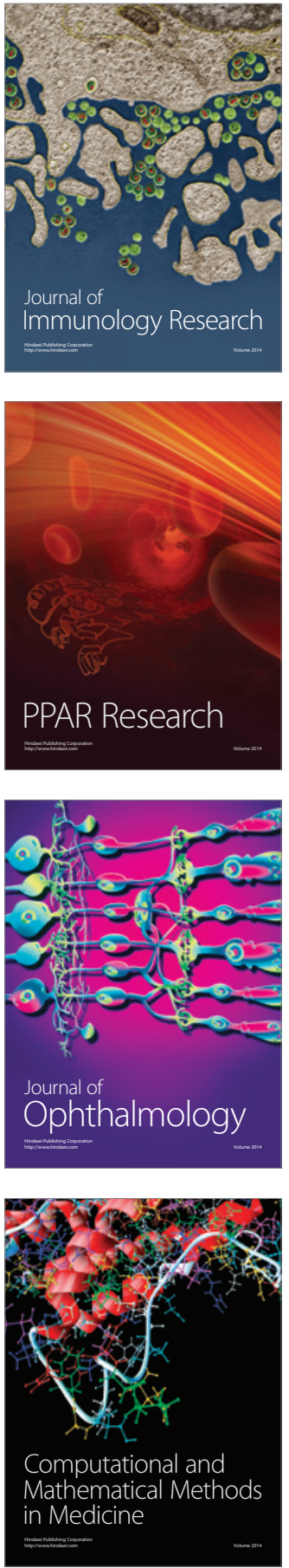

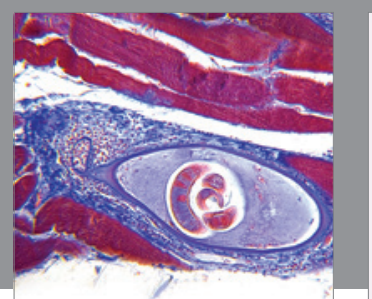

Gastroenterology Research and Practice

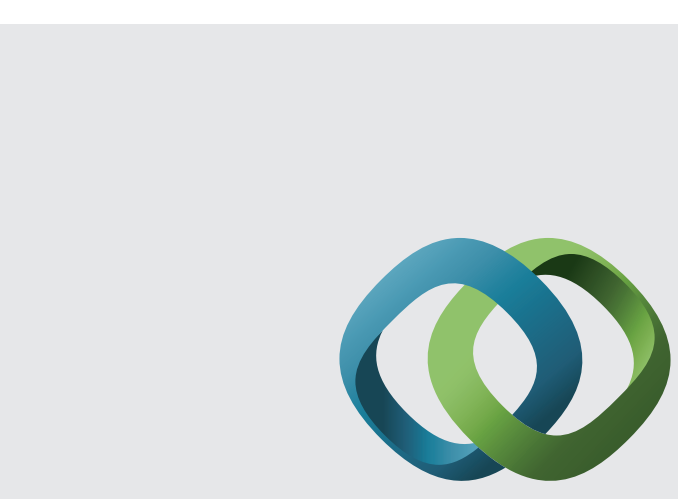

\section{Hindawi}

Submit your manuscripts at

http://www.hindawi.com
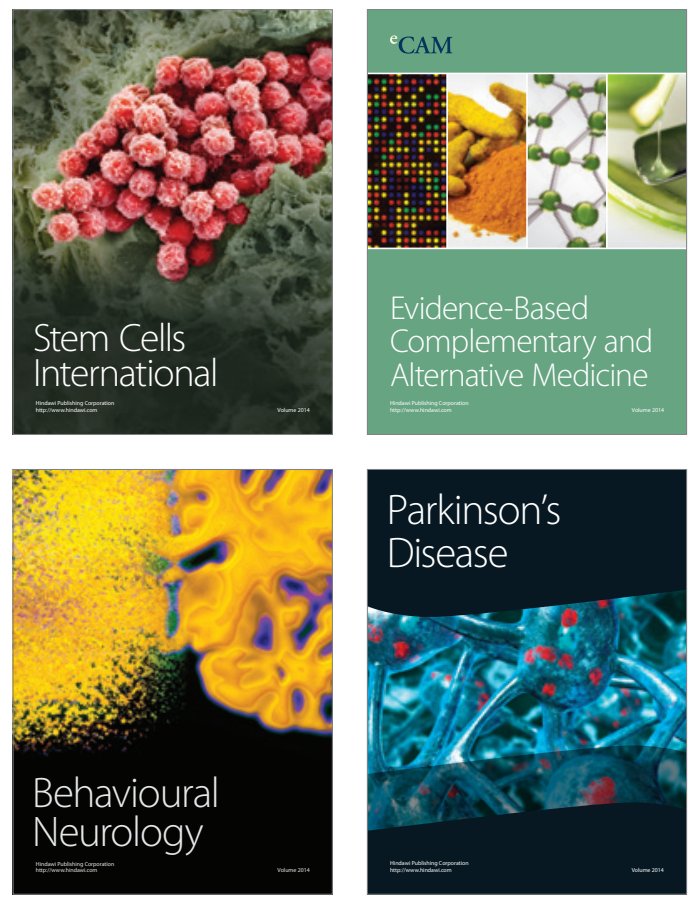
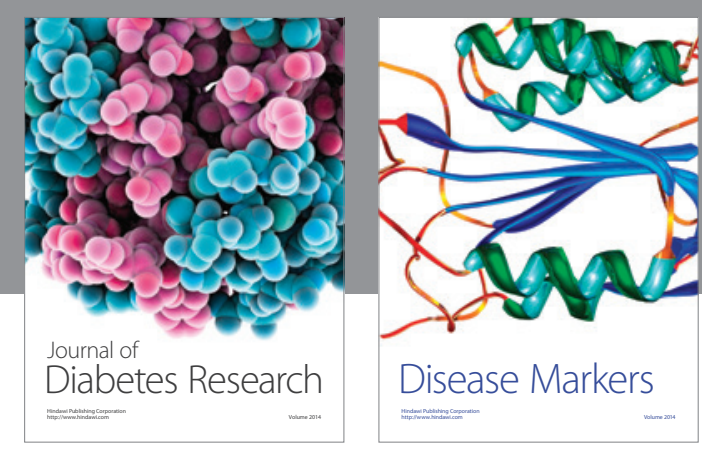

Disease Markers
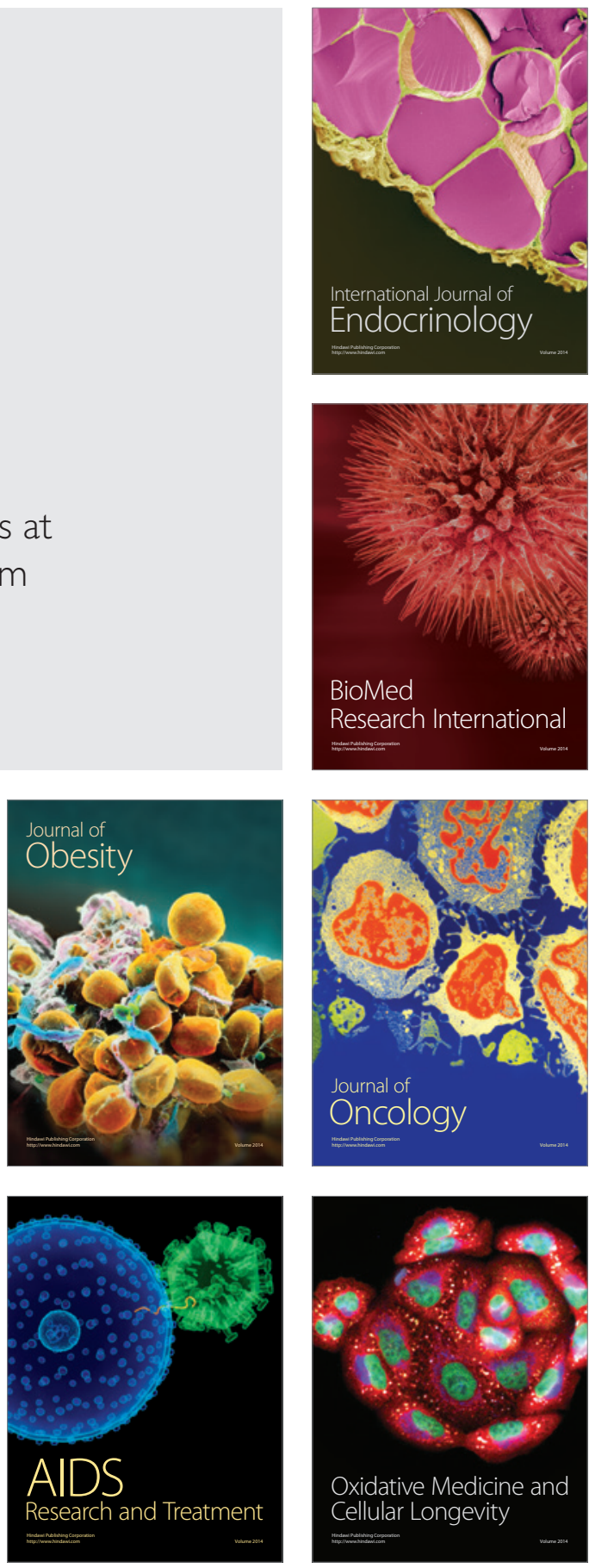